\title{
Proteínas Cry de Bacillus thuringiensis y su interacción con coleópteros
}

\author{
Silvio Alejandro López-Pazos ${ }^{1,2}$, Jairo Cerón²
}

\begin{abstract}
1. Grupo Bazeri, Facultad de Ciencias de la Salud, Universidad Colegio Mayor de Cundinamarca 2. Grupo de Biopesticidas, Instituto de Biotecnología, Universidad Nacional de Colombia Bogotá D.C.
\end{abstract}

Email: alejandrolopezpazos@yahoo.com

Recibido: 02-09-10 / Aceptado: 28-12-10

\begin{abstract}
Resumen
El Manejo Integrado de Plagas es un plan fundamental en la agricultura de conservación que armoniza los métodos químicos y biológicos afín de proteger los ecosistemas agrícolas y sus recursos naturales (agua, suelo, aire). El orden Coleóptera es uno de los problemas entomológicos más importante en los cultivos comerciales causando pérdidas de hasta 15\%. Se utilizan estrategias de control de insectos tales como técnicas culturales, enemigos naturales, entomopatógenos y agentes químicos. Bacillus thuringiensis (Bt) es una bacteria entomopatógena ampliamente utilizada en el control de insectosplaga de los ordenes Lepidóptera, Coleóptera y Díptera. El factor de virulencia de Bt más importante son las proteínas Cry. Varias proteínas Cry tienen actividad letal contra los insectos coleópteros como CrylB, Cryll, Cry3, Cry7, Cry8, Cry9, Cryl4, Cry22, Cry23, Cry34, Cry35, Cry36, Cry37, Cry43 y Cry55. Se ha encontrado que cepas de Bt tipo israelensis son activas contra coleópteros. En esta revisión nosotros presentamos los principales ítems relacionados con la actividad biológica de Bt sobre coleópteros-plaga.
\end{abstract}

Palabras clave: Bacillus thuringiensis, Coleoptero, Cry, Receptor

\begin{abstract}
Integrated Pest Management is a key plan in conservation agriculture to pest control that joins chemical and biological methods to protect crop ecosystem and surrounding natural resources (water, soil, air). Coleoptera order is an important entomological problem in commercial crops causing important losses at least up 15\%. Several management strategies are used in their control such as cultural techniques, natural enemies, entomopathogens and chemical agents. Bacillus thuringiensis $(B t)$ is an entomopathogenic bacteria used widely in pest insect control of Lepidoptera, Coleoptera and Diptera orders. The most important virulence factor of Bt are Cry proteins. Several Cry proteins have lethal activity against coleopteran insects such as CrylB, Cryl I, Cry3, Cry7, Cry8, Cry9, Cryl4, Cry22, Cry23, Cry34, Cry35, Cry36, Cry37, Cry43 y Cry55. It has been found that Bt israelensis-like strains are active against coleopterans. In this review we show the most important determinants with relationship to biological activity of Bt against coleopteran-pests.
\end{abstract}

Key words: Bacillus thuringiensis, Coleopteran, Cry, Receptor 


\section{Introducción}

Una de las principales dificultades en los cultivos comerciales son las plagas, organismos que compiten con el hombre por agua y alimentos, incluyendo los vectores que conllevan la transmisión de enfermedades; estas invaden los espacios en los que desarrollan sus actividades y cuya presencia causa el daño de estructuras o bienes (1). Se estima que entre el 35 al $40 \%$ de la producción agrícola mundial es destruida por plagas, y que los insectos contribuyen aproximadamente con $15 \%$ de este daño $(2,3)$. La eficacia del control de plagas animales alcanza únicamente un 39\% si se compara con el $75 \%$ correspondiente a malezas (2). Los escarabajos (orden Coleóptera) comprenden el grupo más variado entre los eucariontes, y se encuentran entre los insectos que causan un mayor grado de perjuicio en agricultura, horticultura y la industria forestal, causando reducciones en la producción y pérdidas económicas y obviamente el uso de pesticidas químicos para su control no es eficiente $(4,5)$. Varios miembros de las familias Curculionidae, Scarabaeidae, Scolytidae, Chrysomelidae y Coccinilidae están presentes en muchos países de Latinoamérica y el Caribe (6).

Por otra parte, uno de los entomopatógenos más destacados es la bacteria Bacillus thuringiensis (Bt), un bacilo Gram positivo ubicuo, esporulador, aerobio facultativo, que oscila entre 1 a 1.2 micrómetros de ancho, y de 3 a 5 micrómetros de largo, nativo del suelo, ampliamente distribuido en el ambiente, perteneciente al orden Eubacteriales, familia Bacillaceae, grupo I del genero Bacillus (7). La observación al microscopio de contraste de fases de un cuerpo paraesporal refringente, durante la fase de esporulación, permite su diferenciación de otras especies del complejo Bacillus (7). Esta inclusión paraesporal proteica (ICP), ó $\delta$-endotoxina, resulta del ensamblaje de unidades polipeptídicas de varios pesos moleculares $(8,9)$. La actividad de $B t$ es atribuida, amplia o completamente (dependiendo del insecto), a las ICPs y su importancia radica en su toxicidad contra larvas de insectos-plaga de los órdenes Lepidóptera, Coleóptera, Díptera, Himenóptera y Hemíptera (10).
$B t$ es la bacteria entomopatógena más usada como biopesticida, sola o en combinación con pesticidas químicos, en la protección de especies vegetales, agricultura comercial y contra vectores de enfermedades humanas (malaria, dengue, fiebre amarilla, filariasis). $B t$ tiene diversas ventajas que se derivan principalmente de su alta especificidad contra los insectos susceptibles, su inocuidad hacia el medio ambiente, la entomofauna benéfica y demás organismos vivos, incluyendo el hombre, además de una incidencia escasa de fenómenos de resistencia (9). $B t$ representa aproximadamente $90 \%$ del mercado de biopesticidas el cual asciende a 600 millones de dólares (11). Por otro lado, la ingeniería genética se ha utilizado para la introducción de genes de $B t$ en cultivos afín de conferir resistencia a insectos-plaga, los genes que codifican para las $\delta$-endotoxinas han sido transferidos y expresados en más de 26 diferentes especies de plantas (12). Estos cultivos han causado una disminución importante en uso de plaguicidas químicos, que se estima entre 60 a $80 \%$, aproximadamente 21000 toneladas $(13,8)$.

En esta revisión se presenta los principales avances en el estudio de $B t$, con un énfasis especial de los datos encontrados en la actividad tóxica de la bacteria hacia individuos pertenecientes al orden Coleóptera causantes de pérdidas económicas en la agricultura comercial.

\section{La toxina Cry.}

La $\delta$-endotoxina es el resultado del ensamblaje de varias unidades polipeptídicas de diferentes pesos moleculares, que oscilan entre 27 y $140 \mathrm{kDa}$, que se han denominado Cry (del inglés crystal) o Cyt (del inglés cytolitic); una proteína Cry es una inclusión parasporal proteínica de $B t$ que presenta efectos tóxicos verificables experimentalmente sobre un organismo susceptible, o bien una proteína que posee una obvia similaridad de secuencia con alguna proteína Cry conocida (14). El resultado final de la manera en que la proteína Cry ejecuta su actividad letal conlleva la formación de poros líticos en la membrana apical del intestino medio del insecto susceptible mediada por el reconocimiento de un receptor proteico $(8)$. 
La estructura tridimensional de las toxinas Cry presentan una organización biológicamente relacionada con su actividad, con tres dominios funcionales. El dominio I consiste de un paquete de siete $\boldsymbol{\alpha}$-hélices antiparalelas (hidrofóbicas y anfipáticas), donde la quinta hélice está rodeada por las demás. Se considera que este dominio es responsable de la formación de poros en el epitelio intestinal del organismo susceptible, donde una horquilla helicoidal hidrofóbica (a4-a5) inicia la generación de una estructura que envuelve las hélices anfipáticas, con las caras hidrofilicas formando el lumen del canal iónico, aunque también podría deberse a la unión de las hélices hidrofóbicas a5 y a6 para formar un loop en el extremo de la estructura abriendo espacio a manera de navaja e insertándose en la superficie de la membrana $(8,9,15,16)$. El dominio II tiene tres láminas antiparalelas $\beta$ distribuidas en una topología tipo "llave griega", acomodada a manera de un $\beta$-prisma. Este dominio presenta similaridad a los sitios de unión antígeno-anticuerpo, y a moléculas tipo lectina, debido a los loops de superficie expuestos en los ápices de las tres $\beta$ láminas, por ello se considera como la sección que reconoce el receptor (9). El último dominio funcional consiste de dos láminas $\beta$ antiparalelas dobladas formando un $\beta$ sándwich. Esta sección está involucrada en el mantenimiento de la integridad estructural de la toxina ante la proteólisis en el intestino del organismo susceptible, participa en la unión al receptor, penetración en la membrana celular y en la formación de canales iónicos que generan desbalance osmótico $(9,15,17)$.

Hay cinco bloques de secuencias de aminoácidos conservados entre las proteínas Cry (9). El bloque 1 contiene cinco hélices del dominio I y su estructura altamente conservada hace pensar que está implicado en la formación del poro. La localización central de estas hélices dentro del dominio I sugiere un papel esencial en el mantenimiento de la integridad estructural del haz (17). El bloque 2 incluye siete hélices de dominio I y la primera lámina $\beta$ del dominio II, estas dos estructuras comprenden la región de contacto entre estos dos dominios. Hay tres puentes salinos entre los dominios I y II en las toxinas Cry1Aa y Cry3A, esto puede ser importante si el dominio I cambia su orientación relativa para la interacción con el receptor y para mantener la forma globular de la proteína (9). Los bloques 3, 4, y 5 están en cada una de las tres cadenas dentro del dominio III (18). El bloque 3 contiene la ultima lamina $\beta$ del dominio II, una estructura involucrada en las interacciones entre los dominios I y III. Las dos argininas centrales del bloque 4 estarían envueltas en los puentes salinos, afectando el cristal o la agregación oligómerica. La primera y última arginina son solventes expuestos y están implicados en la función del canal (9).

\section{Mecanismo de acción de las toxinas Cry en insectos coleópteros.}

La toxina Cry logra su efecto formando poros líticos sobre las células del intestino medio del insecto susceptible. El conjunto de reacciones que se llevan a cabo para que una toxina Cry ejerza su efecto han sido estudiadas primordialmente en el contexto Lepidóptera. Se han propuesto tres modelos que explicarían este fenómeno biológico (16).

El modelo de Bravo propone que posterior a la ingestión de la espora y el cristal de $B t$, estos últimos se solubilizan bajo la fisiología alcalina del intestino medio de la larva susceptible, liberándose la protoxina que a su vez es clivada por proteasas (tripsinas o quimiotripsinas) dejando un fragmento activo de aproximadamente $60-70 \mathrm{kDa}$; la toxina activa reconoce un receptor tipo caderina (CADR) en la microvellosidad apical intestinal. CADRs son una clase de proteínas transmembrana con un dominio citoplasmático y un ectodominio extracelular que consiste de varias repeticiones $(-12)$, donde las repeticiones 7,11 y 12 interactuarían con el dominio II de la proteína Cry. Luego la hélice $\alpha$-1 es clivada por proteasas asociadas a vesículas de membrana de la microvellosidad apical (VMMA) con lo cual se forman oligómeros que interactúan con otros receptores de la membrana apical, tales como:

- Aminopeptidasa N (APN): es una exopeptidasa anclada a glicosilfosfatidil-inositol (GPI). En lepidópteros se han clasificado en cuatro grupos. Se ha observado que una región de 63 residuos está implicada en el reconocimiento del dominio III de las proteínas Cryl, dependiente de su 
unión con el azúcar $\mathrm{N}$-acetilgalactosamina (GalNac) de la APN $(16,19)$.

- Fosfatasas alcalinas (ALP): son proteínas ancladas a GPI de $-65 \mathrm{kDa}$. Similar a APN, parece ser dependiente del reconocimiento de un oligosacarido de terminación Gal-Nac unido a esta proteína $(16,19)$.

- Glicolípidos, glicoconjugados de $270 \mathrm{kDa}$ y proteínas de $252 \mathrm{kDa}(16,19)$.

Esto lleva a generar poros líticos en las balsas lípidicas de la membrana celular que permiten el paso de iones y agua causando hinchazón, lisis y la posterior muerte del hospedero ya que se genera un ambiente para la germinación de las esporas con una subsecuente septicemia (16).

Un segundo modelo planteado por Zhang especula que la interacción de las toxinas Cry con el receptor CADR esta acoplada a una vía de señalización dependiente de iones $\mathrm{Mg}+$ : la vía adenilciclasa (AC)/Proteína quinasa A (PKA). Básicamente, la unión de la proteína Cry con el receptor activa esta vía de señalización que incluye la estimulación de la proteína $\mathrm{G}$ y a su vez de AC, con el subsiguiente incremento de los niveles de AMP cíclico y la activación de PKA que activaría una vía de señalización intracelular. Esto tendría como consecuencia la desestabilización del citoesqueleto y los canales de iones con la subsiguiente muerte celular (16).

Jurat-Fuentes aporta una propuesta donde la proteína Cry reconoce un receptor CADR y se forman oligomeros que interactúan con APN y con ALP, luego se generan poros líticos con lo cual se activaría una cascada de señalización que estaría regulada por fosfatasas. Esta cascada de señalización incluye el reconocimiento de la toxina con actina que a su vez interactúa con el dominio citosolico de la CADR a través de tirosin-fosfatasas, catenina y actinina. Esta combinación de factores llevaría a la muerte celular (16).

Las características fisiológicas y bioquímicas en el intestino medio de un determinado insecto pueden alterar el proceso bajo el cual la proteína Cry desarrolla su actividad. Aunque se considera que el modo de acción de las toxinas Cry es similar en lepidópteros y coleópteros-plaga se han identificado varias particularidades en estos últimos:

- Para Cry3A, y otras toxinas de actividad anticoleóptera es necesario cortes por enzimas tipo quimiotrípsinas para su solubilización (20).

- El procesamiento proteolítico de la protoxina en coleópteros se da por cisteíno y aspartato proteasas (21). También se encuentran termolisinas y catepsinas (18).

- La importancia del papel de la CADR como receptor de proteínas Cry se ha visto corroborada mediante estudios donde un fragmento del receptor potencializó la toxicidad de la proteína Cry3, y la expresión recombinante de RNA de doble cadena del receptor CADR y su inyección en Tenebrio molitor (Coleoptera) llevo a knockdown del receptor endógeno y resistencia de la plaga a la proteína Cry3 $(22,23)$.

- Unión de la toxina activada a receptores específicos secundarios sobre VMMA de insectos susceptibles que facilitaría su agregación y posterior inserción en la membrana apical intestinal $(18,24)$. Los receptores de toxinas Cry que se han descrito en coleópteros son ALP y $\operatorname{ADAM}$ metaloproteasa $(25,26)$.

- Una vez se ha dado la inserción dentro de la membrana apical, la toxina se vuelve insensible a las proteasas y anticuerpos monoclonales e induce canales de iones o poros no específicos con un diámetro de 1 a 2 nanómetros (nm) en la membrana celular que rompen el potencial de membrana; muy probablemente la agregación previa de toxinas a manera de olígomeros influye en este proceso, mediada por el reconocimiento del receptor $\operatorname{CADR}(9,19,22,25,26)$.

\section{Proteínas Cry de actividad biológica hacia coleópteros-plaga}

Se han descrito algunas proteínas Cry con actividad hacia insectos del orden Coleóptera. Las más utilizadas son las proteínas Cry3. Las toxinas Cry7, Cry8 y Cry9 que muestran relación biológica cercana, mientras que Cry14 y Cry18 presentan una baja 
homología entre ellas y con las demás toxinas. Cry22 y Cry23 se relacionan más cercanamente con Cry37 y Cry38 respectivamente. Además se han descrito proteínas con actividad dual Lepidóptera-Coleóptera (Cry1B y Cry1I), e incluso se conoce la acción de proteínas binarias (Cry34 y Cry35, cuya acción letal resulta de una combinación de ambas toxinas) hacia este orden de insectos. Otras toxinas que afectan este orden de organismos incluyen Cry35, Cry36, Cry37, Cry 43 y Cry 55 (10,27). El análisis filogenético de los dominios de estas proteínas, utilizando la secuencia de aminoácidos, ha llevado a proponer que Cry9 puede ser activa contra coleópteros debido a que su dominio II está relacionado más cercanamente con los dominios II de toxinas anticoleópteras; además se conoce la actividad de la proteína Cry9D hacia coleópteros $(10,28)$.

Alternativamente, se ha publicado la actividad de cepas de $B t$, especialmente la cepa mosquitocida israelensis, con actividad hacia larvas de la broca del café Hypothenemus hampei (Coleoptera: Scolytidae) (29). Los bioensayos con estas cepas fueron realizados utilizando mezclas de espora-cristal, con una dosis de $100 \mu \mathrm{g}$ del complejo espora-cristal $/ \mathrm{cm}^{2}$ de dieta. Las cepas activas fueron israelensis, thompsoni, morrisoni, y malaysiensis. Se encontró que cristales purificados del tipo israelensis (IPS-82) tuvo una concentración letal 50 (CL50) de $219.5 \mathrm{ng}$ de cristal/ $\mathrm{cm}^{2}$ de dieta (29). La serovariedad israelensis de $B t$ produce proteínas Cry4, Cry10 y Cry11 (9).

\section{Ingeniería genética de Bt y los insectos coleópteros.}

La ingeniería genética, o tecnología del ácido dexorribunucleico (DNA) recombinante, abarca un conjunto de metodologías mediante la cual se aíslan y transfieren secuencias de DNA altamente específicas de un organismo y se recombinan con el DNA de otro. El método modifica las características hereditarias de un organismo en un sentido predeterminado mediante la alteración de su material genético. Básicamente, consiste en aislar secciones específicas de la hélice del DNA, como por ejemplo un gen de interés, que puede ser insertado en modelos biológicos diferentes a la fuente natural y de esta forma programar al organismo receptor para que produzca la correspondiente proteína (30).

El modelo investigativo basado en los métodos del DNA recombinante ha permitido lograr grandes adelantos en las aplicaciones de las posibilidades de $B t$ para el control de insectos perjudiciales. Se ha conseguido la clonación de muchos de estos genes para evaluar su actividad toxica contra varias especies de lepidópteros, coleópteros y dípteros utilizando varios hospederos de expresión (cepas acristaliferas de Bt, Escherichia coli, Pseudomonas o Bacillus diferentes a $B t$ entre otros), metodologías variadas de preparación de la toxina (solubilización y activación) y su cuantificación, y pruebas diversas de actividad biológica (contaminación en superficie e incorporación en la dieta, ingestión forzada, etc.) (10). Varias estrategias han permitido modificar proteínas Cry recombinantes con la finalidad de conseguir un espectro de actividad mayor, o una letalidad mejorada. A la adición de factores de potenciación, tales como quitinasas, inhibidores de serinoproteasas, péptidos tipo receptor CADR (CADR12) o toxinas Cyt, se destaca las modificaciones realizadas en la proteína Cry per se, tales como la estrategia de mutagénesis sitio-dirigida con la cual se han modificado residuos específicos en los tres dominios proteicos, con un interés mayor en los loops del dominio II que presumiblemente interactúan con receptores de membrana en la plaga. Estas mutaciones han permitido aumentar la toxicidad hasta 36 veces con respecto a la toxina parental. Otro método que ha coadyuvado en alcanzar proteínas Cry de mejor actividad toxica es el intercambio de dominios funcionales, con lo que se optimizó toxinas cuya letalidad mejoro notablemente, es el caso del hibrido Cry1Ab-Cry1C que aumento la actividad 10 veces hacia Spodoptera exigua (31). Otras modalidades de modificación incluyen la adición de sitios específicos de clivaje, por ejemplo la adición de un sitio quimiotripsina/catepsina $G$ incremento tres veces la letalidad de la proteína Cry3A hacia Diabrotica virgifera (Coleóptera) (32). Las delecciones se han visto que pueden mejorar proteínas previamente inactivas, donde se destaca el caso de las toxinas CryMod, en las cuales se ha realizado la delección de la hélice $\alpha-1$, que resultaron 
en un aumento de afinidad hacia receptores CADR (32). Otras aplicaciones de la tecnología del DNA recombinante en el caso de $B t$ incluye el desarrollo de biopesticidas utilizando cepas modificadas con genes cry de otras cepas, la transformación de bacterias de suelo (por ejemplo Pseudomonas sp.) con genes cry, para mejorar el control de plagas ya que estos microorganismos habitan en el ecosistema planta (12) y la transformación genética que ha producido cultivos resistentes a insectos (9). Otros avances a destacar incluyen:

- La realización de mutagénesis sitio-dirigida en el loop 1 del domio II de la proteína Cry3A (R345A, Y350F, Y351F, $\triangle$ Y350 y $\triangle Y 351)$ con lo que se consiguió aumentar la toxicidad hacia $T$. molitor (Coleóptera: Tenebrionidae), Leptinotarsa decemlineata (Coleóptera: Chrysomelidae) y Chrysomela scripta (Coleóptera: Chrysomelidae) (32).

- La determinación de la estructura tridimensional de la proteína Cry8Ea1 con toxicidad hacia Holotrichia parallela (Coleóptera: Scarabaeidae) (33).

- La transformación genética de una cepa de $B t$, portadora del gen $\operatorname{cry} 8 \mathrm{Ca} 2$, con el gen $\operatorname{cry} 3 \mathrm{Aa} 7$ con lo cual se logro actividad hacia miembros de las familias Scarabaeidae y Chrysomelidae (34).

- A las cepas bacterianas Brevibacillus brevis Ag12 y Bt Ag13, procedentes del intestino de Apriona germari (Coleóptera: Cerambycidae), se les introdujo el gen $\operatorname{cry} 3 A$ para colonizar el insecto y lograr su control (35).

- Introducción una modificación en la proteína Cry3A para que posea el sitio de reconocimiento de las proteasas quimiotripsina/catepsina para lograr toxicidad hacia $D$. virgifera virgifera (Coleóptera: Chrysomelidae) (36).

- La acción biológica de proteínas recombinantes Cry1B y Cry3A sobre larvas de primer instar de H. hampei (Coleoptera: Scolytidae) (37).

- La modificación genética de plantas de papa con el gen que codifica la proteína hibrida SN19, resultado del intercambio de los dominios II de las toxinas Cry1B y Cry1I, con actividad letal hacia el coleóptero L. decemlineata (38).

Existen varios métodos de tamizaje para la determinación de la efectividad de $B t$ sobre un determinado insecto, por ejemplo el uso de preparaciones espora-cristal o purificación de los cristales insecticidas. Sin embargo, el factor que limita el uso de este tipo de metodologías es el consumo de tiempo y esfuerzo en preparar muestras de proteínas activadas bajo idénticas condiciones, que permitan realizar evaluaciones comparativas, además de la presencia de fenómenos de competencia que impide determinar con certeza aquella proteína que causa el efecto biológico (39). La tecnología del DNA recombinante puede ayudar a elevar los niveles de expresión de los genes que codifican para toxinas, si se combinan con promotores fuertes, sitios de unión al ribosoma y apropiadas secuencias iniciadoras y terminadoras, y permite identificar fenómenos de competencia (40). Aunque se llego a considerar que el hospedero de expresión de una proteína Cry (la mayoría de hospederos utilizados son cepas acristaliferas de $B t$ y $E$. coli) podía alterar su actividad toxica, debido a que quizás se afectaban sus propiedades de solubilización, los datos obtenidos no soportan la tesis de que este pudiera ser un factor importante cuando se realiza un ensayo biológico con la toxina recombinante (10).

\section{Las toxinas anticoleópteras Cry1B y Cry3A.}

En la estructura primaria de las proteínas Cry1B y Cry3A se observan varias regiones que se han caracterizado como importantes para la actividad toxica, y su similaridad entre ellas (Figuras 1 y 2) (16, 41). El alineamiento entre estas toxinas (Figura 1) presenta regiones conservadas, cuando se observa aquellas que han sido descritas como importantes en el mecanismo de acción de las toxinas Cry1, se encuentra que sus contrapartes en la proteína Cry3A son similares en los tres dominios, más no es así al analizar la correspondencia en residuos de importancia toxica de Cry3A en el producto toxico del gen $\operatorname{cry} 1 B$; si se examina las franjas de los loops del dominio II, que se han correlacionado con el reconocimiento del receptor, hay correspondencias. 
Cry1B M....... . TSNRKNENEII .... NAVSNHSAQMDL . . . . . LPDARIEDSLC I 36

Cry3 MIRKGGRKMNPNNRSEHDTIKTTENNEVPTNHVQYPLAETPNPTLEDLNYKEFLRM 56

Cry1B AEGNN I DPFVSAST - . - VQTGINIAGR I LGVLGVPFAGQLASFYSFLVGELWPRGR 89

Cry3 TADNNTEALDSSTTKDVIQKG ISVVGDLLGVVGFPFGGALVSFYTNFLNTIWP - SE 111

Cry1B DQWE I F LEHVEQL I NQQ I TENARNTALARLQGLGDSFRAYQQSLEDWLENRDDAR - 144

Cry3 DPWKAFMEQVEALMDQK I ADYAKNKALAELQGLQNNVEDYVSALSSWQKNPVSSRN 167

Cry1B - - TRSVLYTQY I ALELDFLNAMPLFAIRNQEVPLLMVYAQAAN L HLLLLDASLFG 198

Cry3 PHSQGRIRELFSQAESHFRNSMPSFA I SGYEVLFLTTYAQAANTHLFLLKDAQ I YG 223

Cry1B SEFGLTSQE I QRYYERQVERTRDYSDYCVEWYNTGLNSLRGTNAASWVRYNQFRRD 254

Cry3 EEWGYEKED I AEFYKRQLKLTQEYTDHCVKWYNVGLDKLRGSSYESWVNFNRYRRE 279

Cry1B LTLGVLDLVALFP\$YDTRTYPINTSAQLTREVYTDAIGATGVNMASMNWYNNNAPS 310

Cry3 MTLTVLDLIALFPLYDVRLYPKEVKTELTRDVLTDPI - - VGVN - - NLRGYGT - . - T 328

Cry1B FSA IEAAA IRSPHLLDFLEQLTIFSA - SSRWSNTRHMTYWRGHT I QSRP- I GGG- - 362

Cry3 FSN IENY - IRKPHLFDYLHRIQFH RFQPGYYGNDSFNYWSGNYVSTRPSTGSTD 383

Cry1B LNTS LHGATNTS INPV - TLRFASR Q VYRTESYAGVL LW - G I YLEP I HGVPTVRFN 415

Cry3 TISPF YG - - NKSSEPVQN LEFNGEKVYRAVAINTILAVWPSAVY - . - SGVTKVEFS 433

Cry1B FTNPQN I SDRGTANY @ ESPGLQLKDSETELPPETTERPNYESYSHRLSH I G I 471

Cry3 QYNDQT - DEASTQTYDSK - RNVGAVSWDS I DQLPPETTDEPLEKGYSHQLNYVMCF 487

Cry1B LQ_SRVNVPVY SWTHRS DRTNT I GPNR I TQ I PMVKASELPQGT TVVRGPGF TGG 525

Cry3 LMQGSRGTI PVLTWTHKSVDFFNMIDSKK I TQLPLVKAYKLQSGASVVAGPRFTGG 543

Cry1B DILRRTNTGGFGP IRVTVNGPLTQRYR I GFRYASTVDFDFFVSRGGTTVNNFRFLR 581

Cry3 DI I QC TENGSAAT I YVTPDVSYSQKYRAR I HYASTSQ I TFTLSLDGAPFNQYYFDK 599

Cry1B TMNSGDELKYGNFVRRAFTTPFTFTQIQD I IRTS I QGLSGNGEVYIDKIE | I PVTA 637

Cry3 TINKGDTLTYNSFNLASFSTPFELSG - - NNLQIGVTGLSAGDKVYIDKIEFIPVN - 652

Figura 1. Alineamiento de la estructura primaria de las proteínas Cry1B y Cry3A. En negrilla se presentan los residuos conservados. Los cuadros azules encierran aminoácidos relacionados con la toxicidad en las proteínas Cry1 con su correspondencia en la toxina Cry1B. Los cuadrados rojos denotan la contraparte para Cry3A $(16,41)$. Los cuadros morados y amarillos representan los loops de superficie del dominio II para los productos de codificación de los genes cry1B y cry3A respectivamente. La línea vertical anaranjada presenta los límites de los dominios para la toxina Cry1B, mientras que la verde indica lo mismo para la proteína Cry3A.

Al superponer las estructuras terciarias de ambas toxinas podemos observar que las principales diferencias estructurales se ubican en los loops del dominio II, Figura 2 (9). En este contexto, sería útil conocer el efecto de mutaciones en ambas toxinas teniendo como base estas observaciones.

\section{Conclusiones}

Aunque se han encontrado varias toxinas Cry activas hacia insectos del orden Coleoptera (10), sin embargo otros trabajos han demostrado la dificultad en identificar factores tóxicos de $B t$ hacia este particular grupo de invertebrados (42, 43). Estas diferencias en respuesta, si tenemos en cuenta la letalidad de $B t$ hacia lepidópteros, puede deberse a varios factores inherentes a la fisiología de estos insectos (Figura 3, A), que se describen a continuación:

- Se ha identificado que proteasas asociadas con las VMMA, en lugar que con el jugo intestinal, rompen la proteína Cry3Aa generando un fragmento de $38 \mathrm{kDa}$, evidenciando que ciertas proteasas actúan específicamente sobre las toxinas Cry y que se localizan en la membrana celular epitelial (44). En cuanto a las proteasas identificadas en coleópteros se ha encontrado que el tipo predominante corresponden a las cisteínoendopeptidasas (catepsina L, papaina, catepsina $B$, y catepsina $\mathrm{H}$ ), que generalmente se combinan 


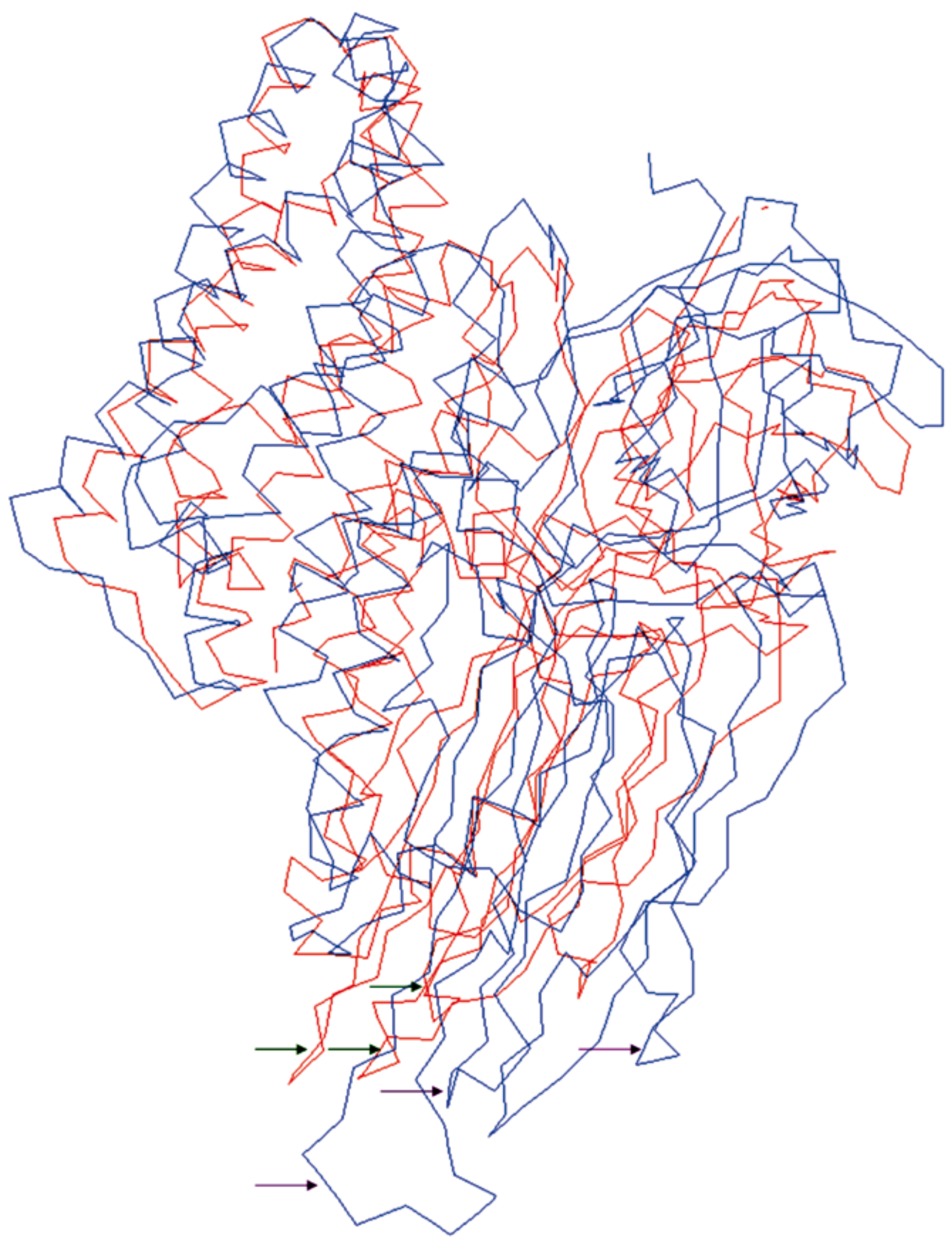

Figura 2. Estructuras tridimensionales superimpuestas de las proteínas Cry1B (azul) y Cry3A (rojo), en base al carbono $\alpha$. Las flechas moradas y verdes indican los loops del dominio II para Cry1B y Cry3A respectivamente. La figura se construyo con el programa Deep ViewSwiss-PdbViewer (http://spdbv.vital-it.ch/). 


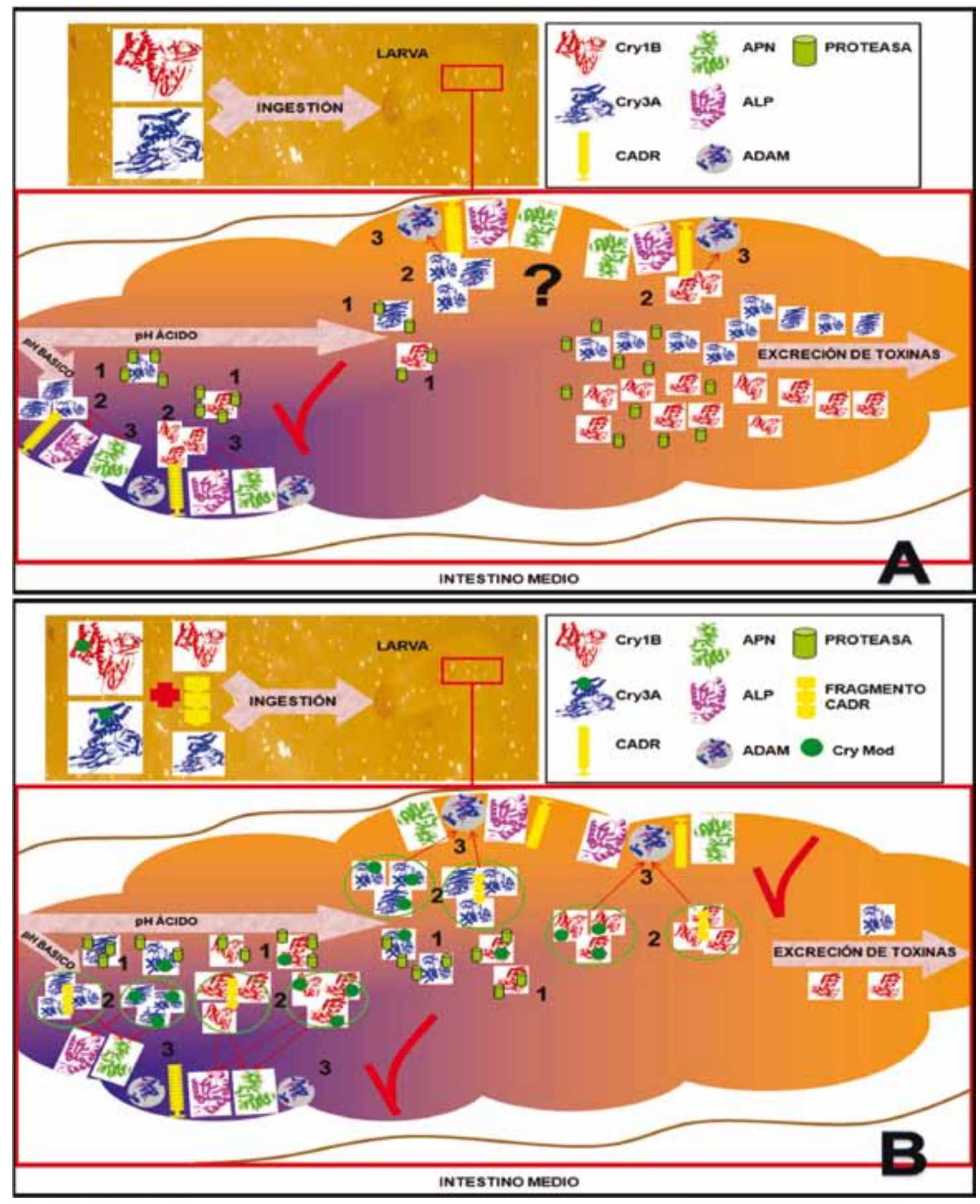

Figura 3. Las toxinas Cry en coleópteros. A. Probable mecanismo de la proteína Cry. La toxina ingerida llega al intestino medio (abajo) de $\mathrm{pH}$ ácido (naranja), con compartimientos básicos (azul). A pH básico la proteína Cry sería activada por proteasas (1), reconocería a CADR y quizás oligomeriza (2), interactuando con ALP, y tal vez APN (3); en acidez la interacción Cry-CADR, con la subsecuente oligomerización, es menos probable y la toxina sufriría el ataque de proteasas, así la mayor parte se excretaría. B. Alternativas de perfeccionamiento de la actividad de la proteína Cry. La larva ingiere proteínas CryMod, o un fragmento de CADR con la proteína Cry estándar, y estas alcanzan compartimientos básicos formando oligomeros resistentes al ataque proteolítico (2) post-activación por proteasas intestinales (o quizás por activación pre-ingestión) (1) logrando interactuar con ALP, y quizás con APN (3); en la región ácida sucedería igual comportamiento, pero los oligomeros interactuarían con receptores tipo ADAM metaloproteasa. La concentración de toxina no eficiente y excretada sería mucho menor. Los símbolos "V" rojos indican actividad biológica positiva, el signo "?" significa que no es claro si existe algún tipo de interacción biológica. Figuras de receptores se diseñaron con el programa Deep View- Swiss-PdbViewer (http://spdbv.vital-it.ch/). 
con aspartato-endopeptidasas (pepsina). Otra clase la constituyen serino-endopeptidasas (tripsina, quimiotripsina, catepsina $\mathrm{G}$, trombina, plasmina y elastasa) con elevada actividad digestiva. También se ha encontrado metaloendopeptidasas (sacarolisina), exopeptidasas (aminopeptidasas), y la omegapeptidasa acilaminoacilpeptidasa. En la mayoría de insectos el procesamiento proteolítico es llevado a cabo por serino-endopeptidasas, por lo que se considera que el $\mathrm{pH}$ ácido de los coleópteros puede estar involucrado en la diferencia en cuanto al tipo de proteasa predominante. La mayoría de proteínas Cry desarrollan su potencial toxico bajo condiciones de $\mathrm{pH}$ alcalino en el intestino (9). Es posible que componentes de membrana afecten la conformación estructural de la proteína exponiendo al solvente los sitios de clivaje para la acción de la proteasa, por ejemplo la observación de bandas proteolíticas adicionales en el extracto intestinal de cepas resistentes de insectos ha llevado a postular que estos cambios se relacionen con dicha resistencia (45). Las proteasas están involucradas en la respuesta innata en el intestino de insectos debido a la modulación y amplificación que ejercen en las cascadas de señalización lo cual conlleva a la activación de mecanismos específicos de defensa tales como el reconocimiento de patógenos, melanización, coagulación e inducción de péptidos antimicrobianos (46 - 50). Se podría pensar que el perfil particular de proteasas en el intestino de coleópteros juega un papel determinante en su susceptibilidad a las proteínas Cry.

- Las aminopeptidasas constituyen un alto porcentaje de las proteínas de la membrana apical del intestino medio en insectos coleópteros (51, 52), se han visto implicadas en la degradación de péptidos terminales y eliminación de los aminoácidos, transducción de señales, clivaje de péptidos de señalización y modulación de sus actividades. En individuos resistentes se ha encontrado que su transcripción aumenta bajo la exposición a las toxinas Cry (44). En coleópteros se ha identificado concentración elevada de aminopeptidasas con actividad incrementada, lo que llevaría a pensar que en este orden de insectos estas moléculas no sirven como receptores de las proteínas Cry, a diferencia de lo que se ha descrito en lepidópteros (44). Aunque en intestinos de insectos se ha observado que las aminopeptidasas requieren un $\mathrm{pH}$ alcalino, mientras que bajo un $\mathrm{pH}$ ácido su actividad se ve disminuida, la presencia de compartimientos alcalinos harían posible niveles de actividad altos (53).

También se ha postulado que la resistencia en coleópteros (u otros insectos) se puede deber a:

- Caída en la afinidad de las toxinas hacia el receptor (54).

- Reducción de sitios de unión para la molécula toxica en el receptor (54).

- Disminución en el número de receptores (54).

- Unión débil en el complejo toxina-receptor (54).

- Excreción aumentada de las moléculas Cry (54).

- Alteraciones en los sitios de reconocimiento en el receptor (54).

- Respuesta inmune elevada, con producción de procoagulantes (tipo hexamerina o lioporina) que forman agregados sobre las proteínas Cry, y actividad esterasa con probable secuestro de las mismas toxinas (54).

- El papel que juega la microbiota asociada al intestino del insecto, ya que se ha asociado una carga bacteriana elevada (determinada en huevos e intestino) a un estado inmune activo en el invertebrado, y cuya transmisión está ligada maternalmente, a una tolerancia mayor a $B t(55)$.

La evidencia apunta principalmente a dificultades con el reconocimiento del receptor CADR y la formación de oligomeros que reconozcan proteínas de membrana, lo cual se encuentra de acuerdo con lo propuesto por el modelo de Bravo (16). Se ha descrito que la utilización de un fragmento del receptor CADR correspondiente a CR12 (repetición CR8 a CR10) de $D$. virgifera virgifera aumentó la actividad toxica de las proteínas Cry3Aa y Cry3Bb para los coleópteros L. decemlineata, D. undecimpunctata howardi, y 
D. virgifera virgifera, entre -2 a 13 veces (23). La identificación del receptor CADR en T. molitor (Coleóptera: Tenebrionidae) llevó a comprender que la región proximal CR9-11, similar a CR8-10, es importante en el reconocimiento de la proteína Cry (22). En otros estudios se encontró que la delección de la hélice $\alpha-1$ de toxinas Cry1 (CryMod) generó estructuras oligomericas, y por ende efectuar su capacidad lítica, sin el previo reconocimiento del receptor CADR, en insectos resistentes a este tipo de proteínas (41). Sería interesante utilizar las estrategias que coadyuvan con la actividad de las proteínas Cry, ya sea empleando fragmentos del receptor CADR de la región proximal al sitio de inserción en la membrana celular, o generando toxinas CryMod capaces de formar oligomeros que interactuen con receptores de membrana, probablemente con la proteína tipo ADAM metaloproteasa que requiere un $\mathrm{pH}$ ácido $(\mathrm{pH}$ 6.5) para su actividad prolyl-endopeptidasa (Figura 3, B) (56). Esto unido al diseño de mejores toxinas Cry, por medio de experimentos de mutagénesis sitio-dirigida o de intercambio de dominios, y la identificación de nuevas toxinas anticoleópteras en $B t \mathbf{u}$ otros organismos, podría repercutir en una estrategia efectiva de control biológico de este grupo de insectos aplicando la tecnología basada en $\mathrm{Bt}$.

\section{Referencias}

1. Environmental Protection Agency, EPA. 2002. Federal Insecticide,Fungicide, and Rodenticide Act (FIFRA) Inspection Manual. Chapter Two: Pesticide Law and Definitions. P. 22.

2. Oerke E.-C. 2006. Crop losses to pests. Journal of Agricultural Science. 144: 31-43.

3. Krattiger A. F. 1997. Insect Resistance in Crops: A Case Study of Bacillus thuringiensis (Bt) and its Transfer to Developing Countries. ISAAA Briefs No. 2. Ithaca, New York: International Service for the Acquisition of Agrobiotech Applications. P. 42.

4. Wang L, Wang S, Li Y, Paradesi MSR, Brown SJ (2007) BeetleBase: the model organism database for Tribolium castaneum. Nucleic Acids Res 35: D476-D479.

5. Potter D.A., Powell A.J., Spicer P.G. et al. 1996. Cultural practices affect root-feeding white grubs (Coleoptera: Scarabaeidae) in turfgrass. J. Econ. Entomol. 89:156-164.

6. Hill D. S. 1987. Agricultural insect pests of temperate regions and their control. Ed. Cambridge University Press. Cambridge UK, pp 258-437.

7. Porcar, M. y V. Juárez-Pérez. 2004. Aislamiento y establecimiento de una colección de Bacillus thuringiensis. En Bacillus thuringiensis en el control biológico. Bravo, A. y Cerón, J. eds. Universidad Nacional de Colombia. Bogotá, Colombia. pp. 69-100.

8. Roh JY, Choi JY, Li MS, Jin BR, Je YH. 2007. Bacillus thuringiensis as a Specific, Safe, and Effective Tool for Insect Pest Control. J. Microbiol. Biotechnol. 17: 547-559.
9. Schnepf, E., Crickmore, N., Van Rie, J., Lereclus, D., Baum, J., Feitelson, J., Zeigler, D.R., Dean, D.H. 1998. Bacillus thuringiensis and Its Pesticidal Crystal Proteins. Microbiol. Mol. Biol. Rev. 62: 775-806.

10. van Frankenhuyzen K. 2009. Insecticidal activity of Bacillus thuringiensis crystal proteins. J Invertebr Pathol. 101: 1-16.

11. Sanchis V., Bourguet D. 2009. Bacillus thuringiensis: applications in agricultura and insect resistance management-a review. In Sustainable Agriculture. Lichtfouse et al. (eds.). Pp. 243-255.

12. Cerón, J. 2004. Productos comerciales: nativos y recombinantes. En Bacillus thuringiensis en el control biológico. Bravo, A. y Cerón, J. eds. Universidad Nacional de Colombia. Bogotá, Colombia. pp. 123-147

13. Bale J. S., van Lenteren J. C. Bigler F. 2008. Biological control and sustainable food production. Phil. Trans. R. Soc. B. 363: 761-776.

14. Crickmore, N., D. R. Zeigler, J. Feitelson, E. Schnepf, J. Van Rie, D. Lereclus, J. Baum, and D. H. Dean. 1998. Revision of the nomenclature for the Bacillus thuringiensis pesticidal crystal proteins. Microbiol. Mol. Biol. Rev. 62:807-813.

15. López-Pazos y Cerón. 2007. Three-dimensional structure of Bacillus thuringiensis toxins: a review. Acta Biol. Colomb. 12: 19-32.

16. Pigott C.R., Ellar D.J. 2007. Role of Receptors in Bacillus thuringiensis Crystal Toxin Activity. Microbiol. Mol. Biol. Rev. 71: 255-281.

17. Aronson, A.I., and Y. Shai. 2001. Why Bacillus thuringiensis insecticidal toxins are so effective: unique features of their mode of action. FEMS Microbiology Letters. 195: 1-8.

18. Bravo, A. 2004. Mecanismo de acción de las proteínas bioinsecticidas de Bacillus thuringiensis. En Bacillus thuringiensis en el control biológico. Bravo, A. y Cerón, J. eds. Universidad Nacional de Colombia. Bogotá, Colombia. pp. 69-100.

19. Bravo A., Gill S.S., Soberón M. 2007. Mode of action of Bacillus thuringiensis Cry and Cyt toxins and their potential for insect control. Toxicon. 49: 423-435.

20. Carroll J., Convents D., Van Damm J., Boets A., Van Rie J., Ellar D.J. 1997. Intramolecular proteolytic cleavage of Bacillus thuringiensis Cry3A $\delta$-endotoxin may facilitate its coleopteran toxicity, J. Invertebr. Pathol. 70: 41- 49.

21. Michaud D., Bernier-Vornais N., Overney S., Yelle S. 1995. Constitutive expression of digestive cysteine proteinase forms during development of the Colorado potato beetle, Leptinotarsa decemlineata Say (Coleoptera: Chrysomelidae). Insect. Biochem. Mol. Biol. 25: 1041-1048.

22. Fabrick J., Oppert C., Lorenzen M.D., Morris K., Oppert B., Jurat-Fuentes J.L. 2009. A novel Tenebrio molitor cadherin is a functional receptor for Bacillus thuringiensis Cry3Aa toxin. J. Biol. Chem. 284: 18401-18410.

23. Park Y., Abdullah M. A., Taylor M. D., Rahman K., Adang M.J. 2009. Enhancement of Bacillus thuringiensis Cry3Aa and Cry3Bb Toxicities to Coleopteran Larvae by a Toxin-Binding Fragment of an Insect Cadherin. Appl. Environ. Microbiol. 75: 3086-3092.

24. Rausell C., García-Robles I., Sánchez J., Muñoz-Garay C., MartínezRamírez A.C., Real M.D., Bravo A. 2004. Role of toxin activation on binding and pore formation activity of the Bacillus thuringiensis Cry3 toxins in membranes of Leptinotarsa decemlineata (Say). Biochimica et Biophysica Acta. 1660: 99- 105.

25. Martins E.S., Monnerat R.G., Queiroz P.R., Dumas V.F., Braz S.V., de Souza Aguiar R.W., Gomes A.C., Sánchez J., Bravo A., Ribeiro B.M. 2010. Midgut GPI-anchored proteins with alkaline phosphatase activity from the cotton boll weevil (Anthonomus grandis) are putative receptors for the Cry1B protein of Bacillus thuringiensis. Insect. Biochem. Mol. Biol. 40: 138-145.

26. Ochoa-Campuzano C., Real M.D., Martinez-Ramirez A.C., Bravo A., Rausell C. 2007. An ADAM metalloprotease is a Cry3Aa Bacillus thuringiensis toxin receptor. Biochem. Biophys. Res. Comm. 362: 437-442.

27. Crickmore, N., Zeigler, D.R., Schnepf, E., Van Rie, J., Lereclus, D., Baum, J, Bravo, A. and Dean, D.H. Febrero 12 de 2011. "Bacillus thuringiensis toxin nomenclature". http://www.lifesci.sussex.ac.uk/Home/ Neil_Crickmore/Bt/ 
28. Bravo, A. 1997. Phylogenetic Relationships of Bacillus thuringiensis $\delta$-endotoxin family proteins and their functional domains. J. Bacteriol. 179: 2793-2801.

29. Méndez-López I., Basurto-Ríos R., Ibarra J. E. 2003. Bacillus thuringiensis serovar israelensis is highly toxic to the coffee berry borer, Hypothenemus hampei Ferr. (Coleoptera: Scolytidae). FEMS Microbiology Letters. 226: 73-77.

30. Dale J. W., von Schantz M. 2002. From Genes to Genomes: Concepts and Applications of DNA Technology. John Wiley \& Sons, Ltd. West sussex, England. P. 21-98.

31. deMaagd R. A., Kwa M. S. G., van der Klei H., Yamamoto T., Schipper B., Vlak J. M., et al. 1996. Domain III substitution in Bacillus thuringiensis deltaendotoxin Cry1 Ab results in superior toxicity for Spodoptera exigua and altered membrane protein recognition. Appl. Environ. Microbiol. 62:1537-1543.

32. Pardo-López L., Muñoz-Garay C., Porta H., Rodríguez-Almazán C., Soberón M., Bravo A. 2009. Strategies to improve the insecticidal activity of Cry toxins from Bacillus thuringiensis. Peptides. 30: 589-595.

33. Guo S., Ye S., Liu Y., Wei L., Xue J., Wu H., Song F., Zhang J., Wu X., Huang D., Rao Z. 2009. Crystal structure of Bacillus thuringiensis Cry8Ea1: An insecticidal toxin toxic to underground pests, the larvae of Holotrichia parallela. J. Struct. Biol. 168: 259-266.

34. Yan G., Song F., Shu C., Liu J., Liu C., Huang D., Feng S., Zhang J. 2009. An engineered Bacillus thuringiensis strain with insecticidal activity against Scarabaeidae (Anomala corpulenta) and Chrysomelidae (Leptinotarsa decemlineata and Colaphellus bowringi). Biotechnol. Lett. 31: 697-703.

35. Zhongkang W., Wei H., Guoxiong P., Yuxian X., Qiang L., Youping Y. 2008. Transformation and expression of specific insecticide gene $B t$ cry $3 A$ in resident endogenetic bacteria isolated from Apriona germari (Hope) larvae intestines. Wei Sheng Wu Xue Bao. 48: 1168-1174.

36. Walters F.S., Stacy C.M., Lee M.K., Palekar N., Chen J.S. 2008. An engineered chymotrypsin/cathepsin G site in domain I renders Bacillus thuringiensis Cry3A active against Western corn rootworm larvae. Appl. Environ. Microbiol. 74: 367-374.

37. López-Pazos S.A., Cortázar J.E., Cerón J.A. 2009. Cry1B and Cry3A are active against Hypothenemus hampei Ferrari (Coleoptera: Scolytidae). J Invertebr Pathol 101: 242-245.

38. Naimov S., Dukiandjiev S., de Maagd R.A. 2003. A hybrid Bacillus thuringiensis delta-endotoxin gives resistance against a coleopteran and a lepidopteran pest in transgenic potato. Plant. Biotechnol. J. 1:51-57.

39. Haffani Y.Z., Cloutier C., Belzile F.J. 2001. Bacillus thuringiensis Cry3Ca1 protein is toxic to the Colorado potato beetle, Leptinotarsa decemlineata (Say). Biotechnol. Prog. 17:211-216.

40. Ben-Dov E., Boussiba S., Zaritsky A. 1995. Mosquito Larvicidal Activity of Escherichia coli with Combinations of Genes from Bacillus thuringiensis subsp. Israelensis. Journal of Bacteriology.177: 2851-2857.

41. Soberón M., Gill S.S., Bravo A. 2009. Signaling versus punching hole: How do Bacillus thuringiensis toxins kill insect midgut cells? Cell. Mol. Life Sci. 66: 1337-1349.
42. López-Pazos S.A., Martínez W., Castillo A.X., Cerón J. 2009. Presence and significance of Bacillus thuringiensis Cry proteins associated with the Andean weevil Premnotrypes vorax (Coleoptera: Curculionidae). Rev. Biol. Trop. 57: 1235-1243.

43. Hernández, S., R. Andrew, Y. Bela \& J. Ferré. 2005. Isolation and toxicity of Bacillus thuringiensis from potato-growing areas in Bolivia Carmen. J. Invertebr. Pathol. 88: 8-16.

44. Loseva O., Ibrahim M., Candas M., Koller C. N., Bauer L. S., Bulla Jr L. 2002. Changes in protease activity and Cry3Aa toxin binding in the Colorado potato beetle: implications for insect resistance to Bacillus thuringiensis toxins. Insect Biochem. Mol. Biol. 32: 567-577.

45. Forcada C., Alcacer E., Garcera M.D., Tato A., Martínez, R. 1999. Resistance to Bacillus thuringiensis Cry1Ac toxin in three strains of Heliothis virescens: proteolytic and SEM study of the larval midgut. Arch. Insect Biochem. Physiol. 42: 51-63.

46. Hoffmann J. A., Kafatos F. C., Janeway C. A., Ezekowitz R.A.B. 1999. Phylogenetic perspectives in innate immunity. Science. 284: 1313-1317.

47. Barillas-Mury C., Wizel B., Han Y.S. 2000. Mosquito immune responses and malaria transmission: lessons from insect model systems and implications for vertebrate innate immunity and vaccine development. Insect Biochem. Mol. Biol. 30: 429-442.

48. Jiang H., Kanost M.R., 2000. The clip-domain family of serine proteinases in arthropods. Insect Biochem. Mol. Biol. 30: 95-105.

49. Dimopoulos G., Richman A., Muller H., Kafatos, F.C. 1997. Molecular immune responses of the mosquito Anopheles gambiae to bacteria and malaria parasites. Proc. Natl. Acad. Sci. USA. 94: 11508-11513.

50. Han Y. S., Thompson J., Kafatos F.C., Barillas-Mury C. 2000. Molecular interactions between Anopheles stephensi midgut cells and Plasmodium berghei: the time bomb theory of ookinete invasion of mosquitoes. EMBO J. 19: 6030-6040.

51. Cristofoletti P.T., Terra W.R. 1999. Specificity, anchoring, and subsites in the active center of a microvillar aminopeptidase purified from Tenebrio molitor (Coleoptera) midgut cells. Insect Biochem. Mol. Biol. 29: 807-819.

52. Cristofoletti P.T. Terra W.R. 2000. The role of amino acid residues in the active site of a midgut microvillar aminopeptidase from the beetle Tenebrio molitor. Biochem. Biophys. Acta. 1479: 185-195.

53. Kaiser-Alexnat R. 2009. Protease activities in the midgut of Western corn rootworm (Diabrotica virgifera virgifera LeConte). J. Invertebr. Pathol. 100: 169-174.

54. Bravo A, Soberón M. 2008. How to cope with insect resistance to $B t$ toxins? Trends Biotechnol. 26: 573-579.

55. Hernández-Martínez, P., Naseri B., Navarro-Cerrillo G., Escriche B., Ferré J., Herrero S. 2010. Increase in midgut microbiota load induces an apparent immune priming and increases tolerance to Bacillus thuringiensis. Environmental Microbiology. 12: 2730-2737.

56. Carty T. J., LoPresti-Morrow L. L., Mitchell P. G., McNiff P. A., McClure K. F. 1999. New Insights into Disintegrin Metalloproteases. Inflamm. res. 48: 229-231. 